\title{
An experimental Study on immediate effect of direct barefoot contact with earth on prehypertension
}

\author{
Shivayogappa S Teli ${ }^{1}$, Senthil Velou $\mathrm{M}^{2}$, Paramasivam $\mathrm{L}^{3}$ and Divya $\mathrm{D}^{4}$ \\ ${ }^{1}$ Dr Shivayogappa S Teli, Associate Professor, Department of Physiology, ${ }^{2}$ Dr Senthil Velou M, Professor, Department \\ of Physiology, ${ }^{3}$ Dr Paramasivam L, Professor, Department of Physiology. All are affiliated to Sri Manakula Vinayagar \\ Medical College and Hospital, Puducherry, India, ${ }^{4}$ Dr Divya D, Assistant Professor, Department of Physiology, \\ Government Medical College, East Yakkara, Palakkad, Kerala, India.
}

Address for Correspondence: Dr Shivayogappa S Teli, Associate Professor, Department of Physiology. Sri Manakula Vinayagar Medical College and Hospital, Puducherry, E-mail address: shivateli222@yahoo.com

\begin{abstract}
Background and Objective: Though many factors are involved in the regulation of arterial blood pressure (BP), autonomic nervous system (ANS) plays a crucial role in acute, short-term control. Any imbalance in ANS activity leads to dysregulation of BP and increases the risk of prehypertension. Recently, a few studies have shown that when the body is connected to the earth's surface using conductive patches or wires, there will be an immediate correction of ANS dysfunction. Expecting similar results, the present study was designed to evaluate the short-term effects of direct barefoot contact with the earth, i.e. without using patches or wires, on prehypertension. Methods: After screening 150 participants, 53 prehypertensives were selected for the study. They were randomly assigned into a study group ( $\mathrm{n}=28$ ) and control group $(n=25)$. Each participant from the study group remained barefooted; i.e. in contact with the ground, for a period of an hour, whereas the control group did not have ground contact. Blood pressure was recorded again at the end of one hour and compared. Data were analysed by paired and unpaired ' $\mathrm{t}$ ' test. A ' $\mathrm{P}$ ' value less than 0.005 was considered significant. Results: There was a significant decrease in SBP $(\mathrm{P}<0.0001)$, DBP $(\mathrm{P}<0.0014)$ and MBP $(\mathrm{P}<0.0001)$ of study subjects after an hour of barefoot contact. However, there was no significant change in the control group. Conclusion: Our study results indicate that direct barefoot contact with the earth reduces blood pressure in prehypertensive individuals. Remaining barefoot, whenever possible, can be a simple, cost-effective and innovative method in preventing hypertension.
\end{abstract}

Keywords: Autonomic Nervous System, Barefoot, Blood Pressure, Earth, Prehypertension.

\section{Introduction}

Hypertension, also known as high blood pressure, is a global public health issue. Being labelled as a 'silent killer', it contributes to the burden of heart diseases, kidney failure, stroke and premature death. According to World health organization (WHO), hypertension alone kills 9.4 million people worldwide every year[1].But, this risk cannot be so high. The development of hypertension and its subsequent complicationsare preventable.Prehypertension is considered as an early indicator of clinical hypertension. The Seventh Report of the Joint National Committee on Prevention, Detection, Evaluation, and

Manuscript received: $4^{\text {th }}$ Aug 2015

Reviewed: $19^{\text {th }}$ Aug 2015

Author Corrected: $27^{\text {th }}$ Aug 2015

Accepted for Publication: $14^{\text {th }}$ Sept 2015
Treatment of High Blood Pressure (JNC-VII), suggested that any individual with a systolic blood pressure (SBP) of $120-139 \mathrm{mmHg}$ or a diastolic blood pressure (DBP) of $80-89 \mathrm{mmHg}$ should be considered as pre-hypertensive [2]. Factors like obesity, depression, anxiety, poor sleep, chronic stress, loneliness, smoking, lack of physical activity, etc predispose an individual to prehypertension.

Usually, such individuals are not the targets for antihypertensive drug therapy and should primarily be advised to modify the lifestyle to lower the blood pressure and to reduce the risk of developing hypertension. Preventive measures like consuming healthy diet, salt restriction, smoking cessation, limiting alcohol consumption, weight reduction, regular physical 
activity, effective stress management etc. are commonly practiced to reduce the risk of hypertension [2].

The autonomic nervous system (ANS) plays an important role in short-term regulation of arterial blood pressure (BP) by changing the peripheral resistance and cardiac output, which are the two main regulators of blood pressure. Many experimental studies have observed that an imbalance of ANS activity with increase in sympathetic and decrease in parasympathetic activity plays a central role in the pathogenesis of both prehypertension and essential hypertension [3, 4, 5]. Excessive sympathetic stimulation and/or diminished vagal tone are markers of a stressed cardiovascular system. Certain antihypertensive drugs and lifestyle modifications, especially weight reduction and regular physical activity have been shown to reduce blood pressure by decreasing sympathetic activity and increasing parasympathetic activity to heart [6].

A recently published research suggests that contact of human body to the earth can regularize autonomic dysfunction. These studies carried out on humans have shown a rapid increase in parasympathetic activity [7, $8]$ and reduction in sympathetic nerve activity $[7,9,10]$ after connecting the body to earth using conductive adhesive patches or copper wires (i.e. Earthing). It is possible that the Earth is a natural source of free electrons and the transfer of these negative electrons into our body via earthing can create a stable internal bioelectrical environment for the normal functioning of all body systems [11].

Since the evolution of human life, except for the past few generations, we lived our entire lives primarily in direct physical contact with the earth. Nowadays, however, we are spending the majority of our lifespan wearing rubber-soled (i.e. insulated) footwear, and rarely having direct contact with the earth [11]. Probably, it could be the reason for rising incidences of fatigue, stress, poor sleep, chronic pain and inflammation in our modern society. Current evidences propose that reconnecting the body to earth can restore ANS dysfunction $[7,8,9,10,12,13,14]$, reduce inflammation, chronic pain, muscle stiffness [10], improve sleep, alleviate stress [11, 14], regularize circadian secretion of cortisol [15] and blood viscosity [16].

We have all experienced that walking or sitting barefoot on the grass or sand makes us feel better. But, we never knew that this subjective feeling of well-being is in fact associated with important physiological benefits. This discovery of beneficial effects of earth, i.e. connecting the body to earth via conductive patches or copper wires helps to stabilize ANS activity, can produce a great impact on our health. We hypothesize that whether direct barefoot contact of the body with earth, i.e. without using any conductive patches or wires, can also produce similar effects on the ANS functions. Therefore, the present study was designed to assess the immediate effects of direct barefoot contact with the earth on prehypertension by studying changes in blood pressure.

\section{Materials and Methods}

The present study was conducted in the Research laboratory of the Department of Physiology with the approval of Research and Ethical Committee of the Institution. It was a Cross-sectional study and the students of second year MBBS batch $(n=150)$ were included by purposive sampling method. The participation was entirely voluntary and study was carried out without disturbing their academic schedule. Written informed consent was taken from each participant after explaining the study purpose and procedure. Demographic information was collected from everyone.

After five minutes of rest in the supine position, blood pressure (BP) was recorded twice for each student; with five minute interval between the two recordings. Blood pressure was recorded using a mercury Sphygmomanometer (Diamond, Industrial Electronic and Allied Products, Pune). The appearance and disappearance of Korotkoff soundswere considered for systolic blood pressure (SBP) and diastolic blood pressure (DBP), respectively. The mean blood pressure (MBP) was calculated using a standard formula $(\mathrm{MBP}=$ DBP $+1 / 3$ Pulse Pressure). Measurement of BP was done by the same observer to avoid bias. All the prehypertensive subjects $(\mathrm{n}=53)$ with $\mathrm{SBP}>120-139$ $\mathrm{mm} \mathrm{Hg}$ and DBP $>80-89 \mathrm{~mm} \mathrm{Hg}$ were included in the study after the screening [2]. Participants with known history of Hypertension, Kidney disease, Diabetes Mellitus and other endocrine disorders, Psychiatric illness, BMI $>30$, smoking within 2 hrs, alcohol consumption less than $12 \mathrm{hrs}$ and those taking any medications that affect BP were excluded from the study. 
Participants were randomly assigned into two groups; study group $(n=28)$ and control group $(n=25)$ based on whether they have barefoot contact or not. Each participant from the study group removed his/her shoes or chappals and remained barefooted; i.e. both feet were indirect contact with the ground, for a period of an hour, whereas the control group did not remove their shoes/chappals. All the participants were sitting in a comfortable chair and care was taken to avoid any kind

\section{Results}

The prevalence of prehypertension and hypertension among the $2^{\text {nd }}$ year MBBS students was $35.33 \%$ and $3.33 \%$, respectively. The hypertensive students were excluded from the study and referred to the Department of Medicine for further evaluation. The differences in the mean values of SBP, DBP and MBP were not statistically significant between the two groups during rest, i.e. before barefoot contact. We observed significant changes in SBP, DBP and MBP of the study group participants after an hour of barefoot contact (Table 1); however, the control group didn't show similar changes in their BP (Table 2).

Table-1: Comparison of SBP, DBP and MBP in Study group before and after an hour of barefoot contact

\begin{tabular}{|l|l|l|l|}
\hline \multirow{2}{*}{ Parameters } & \multicolumn{2}{|l|}{ Study group $(\mathrm{n}=28)$} & \multirow{2}{*}{ 'P' value } \\
\cline { 2 - 4 } & $\begin{array}{l}\text { Before observation } \\
(\text { Mean } \pm \text { SD in } \mathrm{mmHg})\end{array}$ & $\begin{array}{l}\text { After observation } \\
(\text { Mean } \pm \text { SD in } \mathrm{mmHg})\end{array}$ & $0.0001^{*}$ \\
\hline SBP & $134.36 \pm 11.02$ & $122.71 \pm 7.97$ & $0.0014^{*}$ \\
\hline DBP & $81.21 \pm 8.95$ & $73.57 \pm 8.02$ & $0.0001^{*}$ \\
\hline MBP & $98.93 \pm 8.59$ & $89.95 \pm 6.79$ & \\
\hline
\end{tabular}

*significant change $\mathrm{P}<0.05$

Table -2: Comparison of SBP, DBP and MBP in control group before and after an hour of observation (without barefoot contact)

\begin{tabular}{|l|l|l|l|}
\hline \multirow{2}{*}{ Parameters } & \multicolumn{2}{|l|}{ Control group $(\mathrm{n}=25)$} & \multirow{2}{*}{ 'P' value } \\
\cline { 2 - 4 } & $\begin{array}{l}\text { Before observation } \\
(\text { Mean } \pm \text { SD in } \mathrm{mmHg})\end{array}$ & $\begin{array}{l}\text { After observation } \\
(\text { Mean } \pm \text { SD in } \mathrm{mmHg})\end{array}$ & 0.1300 \\
\hline SBP & $131.92 \pm 9.14$ & $128.40 \pm 7.19$ & 0.4192 \\
\hline DBP & $76.08 \pm 11.64$ & $78.32 \pm 7.31$ & 0.8911 \\
\hline MBP & $94.69 \pm 9.72$ & $95.01 \pm 6.37$ & \\
\hline
\end{tabular}

\section{Discussion}

In this study, all prehypertensive subjects of the study group had higher mean values of SBP, DBP and MBP at rest, which were reduced to lower levels after an hour of barefoot contact with the ground. The decline in SBP, DBP and MBP was statistically significant. In the control group, excepting a small, insignificant fall in SBP, there was no change in DBP and MBP after an hour of rest. The decreased SBP seen in both the groups could be due to physical rest for an hour. But it was more significant in the study group who were in direct physical contact with the earth. This indicates that the greater reduction in BP of the study group might be due to barefoot contactwith the earth because all other factors influencing BP were similar for both the groups.

ANS plays a major role in beat-to-beat, minute-tominute and hour-to-hour regulation of cardiovascular function. Maintenance of normal blood pressure depends on both cardiac output and peripheral resistance. Sympathetic nerves tothe heart and blood vessels control cardiac output (CO) and peripheral resistance (PR), whereas parasympathetic nerves mainly control heart rate(HR). Therefore, derangement of ANS activity either increased sympathetic or decreased 
parasympathetic activity causes an elevation of BP. Among all the antihypertensive approaches available at present, lifestyle modifications and treatment with drugs like Clonidine, Angiotensin-converting enzyme inhibitors or Angiotensin receptor antagonists, are associated with improvement in ANS function [6].

Considering the role of ANS in short-term regulation of $\mathrm{BP}$, we determine that the reduction seen in BP of majority of prehypertensives after having barefoot contact with the ground for one hour duration can be attributed to the modulatory effect of earth on autonomic nervous system.

Limitations of the study: Firstly, it was a very short duration experimental study, i.e. one hour barefoot contact on prehypertension. We didn't keep the followup record of the BP afterwards. Secondly, we didn't include the established cases of Hypertension in this study. So, we aren't sure whether a short period of direct barefoot contact with the earth can reduce BP in such cases also, if yes, then to what extent. Lastly, effect on the heart rate was not studied. Hence, it's not clear which limb of ANS is modified by barefoot intervention, i.e. sympathetic or parasympathetic nervous system.

\section{Conclusions}

At the beginning of this study, our hypothesis was whether the direct barefoot contact with the earth can modify the ANS activity or not. The results indicate that direct barefoot contact with the earth can also influence ANS function as evidenced by a decreasein elevated BP. If, in future, clinical trials document the beneficial role of barefoot contact on hypertension, then being barefoot (whenever feasible) might prove advantageous to everyone of us in boosting physiological functions, prevention ofhypertension and overall health of mankind.

Acknowledgement: We are very thankful to all the faculties of Department of Physiology and to second year MBBS students for their complete co-operation during the study period.

Funding: Nil

Conflict of interest: None.

Permission of IRB: Yes

\section{References}

1. World Health Organization (WHO). A global brief on hypertension [Inetrnet]. 2013 Apr.[cited 2015 Jun 10]. Available from: http://www.who.int/cardiovascular_diseases/publication s/global_brief_hypertension.pdf.

2. Chobanian AV, Bakris GL, Black HR, Cushman WC, Green LA, Izzo JL Jr, Jones DW, Materson BJ, Oparil S, Wright JT Jr, Roccella EJ; Joint National Committee on Prevention, Detection, Evaluation, and Treatment of High Blood Pressure. National Heart, Lung, and Blood Institute; National High Blood Pressure Education Program Coordinating Committee. Seventh report of the Joint National Committee on Prevention, Detection, Evaluation, and Treatment of High Blood Pressure. Hypertension. 2003 Dec;42(6):1206-52. Epub 2003 Dec 1.

3. Erdogan D, Gonul E, Icli A, Yucel H, Arslan A, Akcay S, et al. Effects of normal blood pressure, prehypertension, and hypertension on autonomic nervous system function. Int J Cardiol. 2011 Aug 18;151(1):50-3. doi: 10.1016/j.ijcard.2010.04.079. Epub 2010 May 15.

4. Wu JS, Lu FH, Yang YC, Lin TS, Chen JJ, Wu $\mathrm{CH}$, Huang YH, Chang CJ. Epidemiological study on the effect of pre-hypertension and family history of hypertension on cardiac autonomic function. J Am Coll Cardiol. 2008 May 13;51(19):1896-901. doi: 10.1016/j.jacc.2007.12.053.

5. Duprez DA. Cardiac autonomic imbalance in prehypertension and in a family history of hypertension. $\mathbf{J}$ Am Coll Cardiol. 2008 May 13;51(19):1902-3. doi: 10.1016/j.jacc.2008.01.045.

6. Mancia G, Grassi G. The autonomic nervous system and hypertension. Circ Res. 2014 May 23;114(11):1804-14. doi: 10.1161/CIRCRESAHA.114.302524.

7. Chevalier, Gaétan, Kazuhito Mori, and James L. Oschman. The effect of earthing (grounding) on human physiology. European Biology and Bioelectromagnetics. 2006 Jan 31 [cited on 2013 Oct 7]; 600-621. Available from:http://www.bioenergyproducts.co.uk/wpcontent/uploads/Physiology1.pdf.

8. G. Chevalier. Changes in pulse rate, respiratory rate, blood oxygenation, perfusion index, skin conductance, 
and their variability induced during and after grounding human subjects for 40 minutes. J Altern Complement Med. 2010; 16(1): 1-7. Available from: www.groundology.com/research/earthing_pulse_rate.pd f.

9. Chevalier G, Sinatra ST, Oschman JL, Sokal K, Sokal P. Earthing: health implications of reconnecting the human body to the Earth's surface electrons. J Environ Public Health. 2012;2012:291541. doi: 10.1155/2012/291541. Epub 2012 Jan 12.

10. Gaétan Chevalier and Stephen T. Sinatra. Emotional Stress, Heart Rate Variability, Grounding, and Improved Autonomic Tone: Clinical Applications. Integrative Medicine[Inetrnet]. Jun/Jul 2011;10(3):1624. Available from:http://imjournal.com/pdfarticles/IMCJ10_3_p16_2 4chevalier.pdf.

11. A. Clinton Ober and Ventura, CA. Grounding the human body to neutralize bioelectrical stress from static electricity and EMFs. ESD JOURNAL [Inetrnet]. January, 2000 [cited on 2014 Jan 10]. Available from:http://www.esdjournal.com/articles/cober/ground. htm.
12. Stephen Sinatra. Earthing and the Nervous System. Spacedoc.com[Inetrnet]. October 2011[cited on 2014 May 25]. Available from: http://www.spacedoc.com/earthing_nervous_system.

13. Sokal P, Sokal K. The neuromodulative role of earthing. Med Hypotheses. 2011 Nov;77(5):824-6. doi: 10.1016/j.mehy.2011.07.046.

14. Gaetan Chevalier and Kazuhito Mori. The effect of earthing on human physiology part2: electrodermal measurements. Subtle Energies and Energy Medicine.2007;18(3):11-34. Available from:http://journals.sfu.ca/seemj/index.php/seemj/articl e/download/9/7.

15. Ghaly M, Teplitz D. The biologic effects of grounding the human body during sleep as measured by cortisol levels and subjective reporting of sleep, pain, and stress. J Altern Complement Med. 2004 Oct;10(5):767-76.

16. Chevalier G, Sinatra ST, Oschman JL, Delany RM. Earthing (grounding) the human body reduces blood viscosity-a major factor in cardiovascular disease. J Altern Complement Med. 2013 Feb;19(2):102-10. doi: 10.1089/acm.2011.0820. Epub 2012 Jul 3.

\section{How to cite this article?}

Shivayogappa S Teli, Senthil Velou M, Paramasivam L and Divya D. An experimental Study on immediate effect of direct barefoot contact with earth on prehypertension. Int $J$ Med Res Rev 2015;3(8):836-840. doi: 10.17511/ijmrr.2015.i8.157. 